Research Article

\title{
Detection of Dengue Virus in Human Blood Samples from Selected Localities of Delhi and NCR
}

\author{
Suresh Chand Kaushik', Sukhvir Singh ${ }^{2}$, Purnima Srivastava ${ }^{3}$ \\ ${ }^{1}$ Department of Life Science and Applied Sciences, Bhagwant University, Ajmer, Rajasthan, India. \\ ${ }^{2}$ National Vector Borne Disease Control Programme, Ministry of Health and Family Welfare, 22-Shamnath Marg, Delhi, India. \\ ${ }^{3}$ Bhagwant University, Ajmer, Rajasthan, India.
}

DOI: https://doi.org/10.24321/0019.5138.201920

\section{I $\quad \begin{array}{lllll}\mathbf{N} & \mathbf{F} & \mathbf{O}\end{array}$}

\author{
Corresponding Author: \\ Suresh Chand Kaushik, Department of Life Science \\ and Applied Sciences, Bhagwant University, \\ Ajmer, Rajasthan, India. \\ E-mail Id: \\ kaushiksureshchand@gmail.com \\ Orcid Id: \\ https://orcid.org/0000-0002-5141-0232 \\ How to cite this article: \\ Kaushik SC, Singh S, Srivastava P. Detection of \\ Dengue Virus in Human Blood Samples from \\ Selected Localities of Delhi and NCR. J Commun \\ Dis 2019; 51(3): 10-14.
}

Date of Submission: 2019-08-17

Date of Acceptance: 2019-09-21

\section{$\begin{array}{llllllll}\mathbf{A} & \mathbf{B} & \mathbf{S} & \mathbf{T} & \mathbf{R} & \mathbf{A} & \mathbf{C} & \mathbf{T}\end{array}$}

A survey for detection of dengue virus in human blood was conducted. The blood filter paper blots of suspected cases of dengue were collected from different localities of Delhi and NCR. These blood spots were tested using rapid diagnostic kits. In all 87 suspected cases were tested for the presence of dengue virus by repeating them for all confirmation. Out of 87 samples 20 were found dengue positive, 56 samples had past infection and 5 cases were having current fever. The positive samples were again confirmed by PCR and about 8 cases were found positive out of 20 cases. The positivity was found very high from October to November 2016. The Sero conversion rate shows that about $35 \%$ of resident are getting new infection each year which is indicator of increasing local transmission. RT PCR can detect low viramia which helps in isolating patient and timely control activities. PCR technique along with conventional kits should be carried out to access cases more accurately, so that control can be targeted to such areas.

Keywords: Aedes aegypti, RT-PCR, IgM, IgG, NS1

\section{Introduction}

Dengue is the most rapidly spreading mosquito-borne viral disease of mankind. It is a major public health concern throughout the tropical and subtropical regions of the world. Almost half of the world's population lived in countries where Dengue is endemic. World Health Organization (WHO) estimates that 50-100 million Dengue infections occur annually with 2200 deaths in more than 100 endemic countries, with a steady increase in the number of countries reporting the disease. ${ }^{1}$ Dengue has been identified as one of the 17 neglected tropical diseases by WHO as mentioned in their first report on neglected tropical diseases. ${ }^{2}$ The loss to the economy is 264 Disability-Adjusted Life Years (DALY ${ }_{s}$ ) per million populations per year. ${ }^{3,4}$ The true numbers are far more, since severe under reporting and misclassification of dengue cases have been documented by the countries. ${ }^{3}$ Approximately 1.8 billion (more than $70 \%$ ) of the population at risk for dengue worldwide live in WHO South East Asia Region (SEAR) and Western Pacific Region which bear nearly $75 \%$ of the current global disease burden due to dengue. ${ }^{5}$

Dengue virus was isolated in India for the first time in 1945. The first evidence of occurrence of dengue fever in the country was reported in 1956 from Vellore district in Tamil Nadu. The first dengue Demorrhagic Fever (DHF) outbreak 
occurred in Calcutta (West Bengal) in 1963. ${ }^{6,7}$ It has been estimated that more than 390 million dengue infections occur every year, of which 96 million manifests clinically and India contributes to about a third global burden of apparent dengue infections. ${ }^{8,9}$

As per India's Integrated Disease Surveillance Programme, more than 100 dengue outbreaks were reported in 2015. ${ }^{10}$ Good laboratory-based disease surveillance is essential for early detection of dengue outbreaks and implementation of effective preventive and control measures. In India, the laboratory capacity for diagnosis of outbreaks under Integrated Disease Surveillance Programme is limited. ${ }^{11}$ Dengue serotype surveillance is important, as large dengue outbreaks tend to follow changes or re-introduction of serotypes. ${ }^{12}$

The four Dengue Virus Types (DENV1-4), called dengue virus serotypes which differ in nucleotide sequence from each other can con-circulate in the endemic areas because the immunity to one serotype does not afford protection from the infection by a heterotrophous serotype. ${ }^{13}$ Though transmission primarily occurs through bite of a vector, there are reports of dengue transfusion and organ transplantations. ${ }^{14}$ Dengue viral infected person may be asymptomatic or symptomatic and clinical manifestations vary from undifferentiated fever to florid hemorrhagic and shock. ${ }^{15-18}$

In endemic areas, early symptoms of dengue fever mimic often prevalent diseases such as chikungunya, malaria, viral infections, typhoid, leptospirosis etc. For confirmation of dengue infection, Government of India recommends use of ELISA based antigen detection test (NS1) for diagnosing the cases from the first day onwards and antibody detection test IGM capture ELISA (MAC-ELISA) for diagnosing the cases after the fifth day of onset of disease. ${ }^{19}$

There is co-circulation and concurrence of infections by multiple DENV serotypes which has become a frequent occurrence in endemic areas which influence clinical expression and accounts for the emergence of Dengue Hemorrhagic Fevers (DHFs). ${ }^{20}$

DENV serotypes and strains within the serotypes are known to vary in their ability to infect and disseminate in mosquitoes. ${ }^{21}$ Dengue serotype 2 strain have been demonstrated to be better adapted and tend to infect the highly demonstrated Ae. aegypti more efficiently. ${ }^{22}$ It is thus considered the principal vector of DENV in urban areas where the species Ae. albopictus is recognized as an important vector in some rural areas.

The Commercial Pathozyme Dengue IgM and IgG (CPD IgM-IgG) test kits are a very good tool for carrying out laboratory-based active surveillance. ${ }^{23}$

Molecular diagnosis based on Reverse Transcription
Polymerase Chain Reaction (RT-PCR) has gradually replaced virus isolation methods for the detection of dengue virus in acute phase serum samples. Considering the threat that dengue poses to the country, continuous monitoring of the viruses circulating in different parts of the country would reveal whether there are changes in the virus population from year to year and/or from place to place.

Although several parts of India are endemic for Dengue, Delhi has been worst hit during the past decades. In 1996, DENV-II genotype 4 was circulating in Delhi. ${ }^{24}$ DENV-II was also reported in 2002 and 2004 while DENV-III in circulation with DENV-II emerged in 2003, replacing DENV-2 in subsequent year. ${ }^{25}$ In 2006, the co-circulation of DENV-1 with predominance of DENV-III, thereby increasing the risk of severity of the disease in population already exposed to a previous serotype. Such study of epidemiological dynamics in population in which $>1$ DENV serotype co-circulate simultaneously is of special significance. ${ }^{26}$

\section{Material and Methods}

Delhi and NCR region reporting on an average of 5000-6000 cases every year. The blood filter paper blots (three spots each from one subject) were brought to the laboratory from suspected fever cases from different localities of Delhi\& NCR namely Noida, Ghaziabad and Faridabad. The samples were taken randomly twice in a month from the hospitals who had already active fever cases screened through rapid kit IgG, IgM and NS1. Randomly samples were collected from different clinical laboratories during August to December 2016 from Delhi \& NCR region to assess the positivity during the study duration.

Blood spots were taken from suspected cases which were already tested using RDT kits. A total of 87 samples were collected for PCR detection. Details of patients were not taken as our objective was to detect fever cases through RT-PCR.

RNA extraction of each bloodspot was done using Qaigen total RNA extraction mini kit (Qaigen, Germany) as per manufacturer instruction. The extracted RNA samples were stored in $-70^{\circ} \mathrm{C}$.

The samples were subjected to RT-PCR within two days of RNA extraction using Qiagen one step RT-PCR kit (Qaigen Germany). The primers and the nucleotide sequences used in this study were those published by Lanciotti et al. (1992) (Table 1), Reverse transcriptase reaction and amplification was carried out in $50 \mathrm{~mL}$ reaction mixture which contained $2 \mu \mathrm{L}$ of each forward and reverse primer, $8 \mu \mathrm{L} 5 \mathrm{X}$ Qaigen one step buffer, $2 \mu \mathrm{L}$ dNTPs, $1 \mu \mathrm{L}$ Q one step enzyme mix, and $25 \mu \mathrm{L}$ RNase free water and $10 \mu \mathrm{L}$ Sample.

Thermal conditions for PCR were: single step rt reaction was carried out at $50^{\circ} \mathrm{C}$ for $30 \mathrm{~min}$ followed by denaturation $95^{\circ} \mathrm{C}$ for $15 \mathrm{~min}$, incubation at $94^{\circ} \mathrm{C}$ for $30 \mathrm{sec}$ for denaturation 
of the cDNA, at $55^{\circ} \mathrm{C}$ for 2 min for primer annealing, and at $72^{\circ} \mathrm{C}$ for 2 min for primer extension for 40 cycles, followed by incubation at $72^{\circ} \mathrm{C}$ for $10 \mathrm{~min}$. The amplified products were visualized by electrophoresis on $2 \%$ agarose gels with ethidium bromide using TAE (40 mM Tris-acetate, $1 \mathrm{mM}$ EDTA) as buffer for the electrophoresis. The bands were visualized under UV light. travelled Asia for at least one. ${ }^{28,29}$ which show high risk to the international travelers in Asia. The sero-conversion rates are seen very high during the transmission season. However, the conversion rate also depends on the population movements in the megacities like Delhi. High population movement from different areas of India may alter both IgM \& IgG. However, new high infection rates (sero-conversion) are indicator of

Table I.Sequence of dengue primers

\begin{tabular}{|c|c|c|}
\hline S. No. & Primer & Sequence \\
\hline 1. & DEN 1 & 5'-TCAATATGCTGAAACGCGCGAGAAACCG-3' \\
\hline 2. & DEN 2 & 5'-TTGCACCAACAGTCAATGTCTTCAGGTTC-3' \\
\hline
\end{tabular}

Table 2.Detection of dengue virus from blood samples in Delhi and NCR (August-December 20 I6)

\begin{tabular}{|c|c|c|c|c|c|c|c|}
\hline $\begin{array}{c}\text { S. } \\
\text { No. }\end{array}$ & Month & Locality & $\begin{array}{c}\text { No. of } \\
\text { sample }\end{array}$ & IgG & IgM & NS1 & RT-PCR \\
\hline 1. & August 2016 & Nithari Sector-30\&Sarfabad (Noida) & 9 & 6 & 2 & 0 & 1 \\
\hline 2. & September 2016 & Khoda Colony \& Railway colony (Ghaziabad) & 22 & 10 & 4 & 2 & 1 \\
\hline 3. & October 2016 & Uttam Nagar \& Najafgarh (Delhi) & 28 & 16 & 6 & 1 & 2 \\
\hline 4. & November 2016 & Mangolpuri \& Raghubir Nagar (Delhi) & 18 & 17 & 7 & 2 & 4 \\
\hline 5. & December 2016 & Sanjay Colony \& Sehatpur Village (Faridabad) & 10 & 7 & 1 & 0 & 0 \\
\hline \multicolumn{2}{r}{} & Total & 87 & 56 & 20 & 5 & 8 \\
\hline
\end{tabular}

The four conventional RT-PCR assays were performed and, in each test, run a volume of $25 \mu \mathrm{L}$ with $5 \mu \mathrm{L}$ nucleic acid extract was used as a template.

\section{Result}

87 suspected cases were tested for the presence of dengue virus by repeating them for all confirmation. Out of 87 samples, 20 were found dengue positive, 56 samples have past infectious and 5 cases were having current fever. The positive samples were again confirmed by PCR and 8 cases were found positive out of 20 cases. The positivity was found high during October and November 2016 (Table 2). Although sample size in the study area was lower, the concurrent cases in the study area were 4431.

\section{Discussion}

Dengue is a viral infection spread mainly through mosquito bite. The infection rate of dengue in our study shows $5.74 \%$ which is a high rate. The sero conversion rates was found to be 35\% (20 IgM positive/56 IgG positive) which also suggest about $35 \%$ of residents are getting new infectious each year. The sample size in this study may be low but it may give trend of dengue infection which shows high transmission during post monsoon season (Aug-Oct). Similar Study by Dhar Chowdhury P et al. ${ }^{27}$ suggested only $56-97 \%$ sero-conversion rates in Dhaka Bangladesh which was very high. In some other study on travels sero-conversion rates were $2.9 \%$ in Dutch travelers and $6.7 \%$ Israeli travelers who increasing local transmission or more new cases reporting. Extensive studies conducted on epidemiology of dengue by Vikram et al. (2016) have included high contribution of asymptomatic positive cases which also increases the local transmission risk. There is need to expedite vector control activities with public awareness programs at various levels in such endemic localities to change behaviour for reducing the mosquito genic conditions supporting dengue in urban cities like Delhi. Although rapid kits are reliable but unable to detect low viremia as was wit nested in PCR which detected more than NS1 detection. This prompt a need of better detection method which could also address low viremic patients also in their initial stage which cloud be helpful for isolating patient and timely control activities.

This makes for a public health interest on local DF burden and epidemiology and offers the platform to improve surveillance, laboratory testing capacity and clinical alertness in the health delivery system in Delhi and NCR. Effective prevention and control programs will depend on improved surveillance designed to provide early warning of dengue epidemics. Thus, there is need to study the occurrence of dengue virus infections during the period following an epidemic to provide information on the endemicity of dengue and to predict further epidemics in Delhi and NCR.

\section{Conclusion}

It is concluded that the positivity against dengue virus was 
found very high from October to November 2016. The Sero conversion rate was found $35 \%$ in residents which are getting new infection each year. This indicates that local transmission is going on. PCR technique along with conventional kits should be carried out to access cases more accurately, so that control can be targeted to such areas. Thus, there is need to study the occurrence of dengue virus infections during the period following an epidemic to provide information on the endemicity of dengue.

\section{Conflict of Interest: None}

\section{References}

1. Aggarwal A, Chandra J, Aneja S et al. An epidemic of dengue hemorrhagic fever and dengue shock syndrome in children in Delhi. Indian Pediatrics 1998; 35: 727-732.

2. Baruah K, Biswas A, Suneesh K et al. Dengue fever: epidemiology and clinical pathogenesis. Major Tropical Disease, Public Health Perspective. Broadway Publishing House, Goa. 2014; 255-271.

3. Baruah K, Dhariwal AC. Epidemiology of Dengue, its preventions and control India. Journal of Indian Medical Association 2011; 109(2): 82-86.

4. Beatty ME, Stone A, Fitzbimous DW et al. Best practices in dengue surveillance; A report from Asia-pacific and Americas Dengue Prevention Boards. PLOs Negi Trop Dis 2010; 4: e890.

5. Bhatt S, Gething PW, Brady OJ et al. The global distribution and burden of dengue. Nature 2013; 496(7446): 504-507.

6. Chen L, Wilson ME. Non-vector transmission of dengue and other mosquito born - Flaviviruses. Dengue Bull 2005; 29: 18-30.

7. Cobelens FG, Groen J, Osterhaus AD et al. Incidence and risk factors of probable dengue virus infection among Dutch travelers to Asia. Trop Med Int Health 2002; 7(4): 331-338.

8. Dar L, Broor S, Sengupta S et al. The first major outbreak of dengue hemorrhagic fever in Delhi, India. Emerging Infectious Disease 1997; 5(4): 587-590.

9. Dhar Chowdhury P, Paul KK, Haque CE et al. Dengue sero-prevalence, sero-conversion and risk factors in Dhaka, Bangladesh. PLOS Neglected Tropical Diseases 2017; 11(3): e0005475.

10. Dutta AK, Biswas A, Baruah K et al. National guidelines, for diagnosis and management of dengue fever/dengue hemorrhagic fever and dengue shock syndrome. Journal of Indian Medical Association 2011; 109(1): 30-35.

11. Fredricks AC, Fernandez Sesma A. The burden of dengue and chikungunya worldwide: Implications for the southern United States and California. Ann Global Health 2014; 18: 466-475.

12. Guzanan MG, Halstead SB, Astrobit Bucky P et al. Dengue. A continuing global threat. Nat Rev Microbiol
2010; 8(12 Suppl): 7-16.

13. Ha DQ, Jhang CM, Ton T et al. Evaluation of commercial pathozyme dengue IgM and IgG test for sero-diagnosis of dengue virus infection. Dengue Bulletin 2000; 24: 97-102.

14. Kabilan L, Balasubramanian S, Keshava $M$ et al. Dengue disease spectrum among infants in the 2001 dengue epidemic in Chennai, Tamil Nadu, India. Journal of Clinical Microbiology 2003; 41(8): 3919-3921.

15. Kalayanarooj S. Clinical manifestations and management of dengue/DHF/DSS. Tropical Medicine and Health 2011; 39 (4 suppl): 83-89.

16. Kumar M, Pasha ST, Mittal V et al. Unusual emergence of guate 98 like molecular genotype of DEN-3 during 2003 dengue outbreak in Delhi. Dengue Bull 2005; 74: 314-22.

17. Lanciotti RS, Calisher $\mathrm{CH}$, Gubler DJ et al. Rapid detection and typing of dengue viruses from clinical samples by using reverse transcriptase-polymerase chain reaction. J Clin Microbiol 1992; 30(3): 545-551.

18. Midterm plan for prevention and control of dengue and chikungunya, New Delhi, NVBDCP, DHS, Ministry of Health and Family Welfare Government of India, 2011.

19. Potasman I, Srugo I, Schwartz E. Dengue sero-conversion among Israeli travelers to tropical countries. Emerg Infect Dis 1999; 5(6): 824-827.

20. Raut DK, Bhola A. Integrate disease surveillance on India: Way forward. Global Journal Medical Public Health 2014; 3(4).

21. Sharma S, Sharma SK, Mohan A et al. Clinical profile of dengue hemorrhagic fever in adults during 1996 outbreak in Delhi, India. Dengue Bulletin 1998; 22: 20-30.

22. Shaya JA, Shepard DS, Siqueha JB et al. Cost of dengue cases in eight countries in the Americas and Asia: a perspective study. American Journal of Tropical Medicine and Hygiene 2009; 80(5): 846-855.

23. Singh UB, Maitra A, Bror S et al. Partial nucleotide sequencing and molecular evolution of endemic causing dengue to stains. J Infect Dis 1999; 180(4): 959-965.

24. Vikram K, Nagpal BN, Pande V et al. An epidemiological study of dengue in Delhi, India. Acta Trop 2016; 153: 21-27.

25. Wilder-Smith A, Yoksan S, Earnest A. Serological evidence for the co-circulation of multiple dengue virus serotypes in Singapore. Epidemical Infec 2015; 133(4): 667-671.

26. World Health Organization and Tropical Disease Research. Dengue: Guidelines for diagnosis, treatment, prevention and control. World Health Organization, Geneva. 2018. Available from: https://www.who.int/ rpc/guidelines/9789241547871/en/. Accessed on 26.07.2019. 
27. World Health Organization and Tropical Diseases Research. Handbook for clinical management of dengue. World Health Organization, Geneva. 2012.

28. World Health Organization Comprehensive Guidelines for preventions and control of dengue and dengue hemorrhagic fever. New Delhi; WHO; SEA RO, 2011. Available from: https://www.who.int/tdr/publications/ documents/dengue-diagnosis.pdf.

29. World Health Organization. First report on neglected tropical diseases: Working to overcome to global impact of neglected tropical diseases. World Health Organization, Geneva. 2010. Available from: https:// apps.who.int/iris/bitstream/handle.

30. World Health Organization. Global Strategy for dengue prevention and control - 2012-2020. World Health Organization, Geneva. 2012.

31. Zhang C, Mammer MP Jr., Chinnawirotpisam P et al. Clade replacements in dengue serotype 1 and 3 are associated with changing serotype prevalence. J Virol 2005; 79(15): 123-130. 